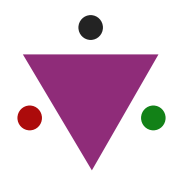

IJCRR

Section: Healthcare

Sci. Journal Impact

Factor: $6.1(2018)$

ICV: 90.90 (2018)

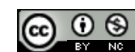

Copyright@IJCRR

\section{Effectiveness of Planned Teaching on Knowledge and Practice Regarding Growth Monitoring of Under-Five Children Among Anganwadi Workers in the Rural Area of Wardha District}

\author{
Khushbu Meshram¹, Archana Mourya², Mayuri Hinge ${ }^{3}$, Lawrence James ${ }^{3}$, \\ Prajakta Mankar ${ }^{3}$
}

\title{
ABSTRACT
}

Background: Weighing the child at regular intervals allows parents and pediatricians to see weight fluctuations and give guidance to the mother based on this weight change.

Aim: To determine the effectiveness of Structured Teaching Programme (STP) on the knowledge and practice regarding growth monitoring among the Anganwadi workers.

Methods: A pre-experimental pre-test, the post-test research design was used to conduct this study with convenience sampling to collect data from 60 Anganwadi workers using structured questionnaire. After collecting pre-test data, STP was organized for the intervention of growth monitoring to samples. Seven days were provided to the samples for utilizing STP which was organized for 45-50 minutes through lecture, discussion and planned Audio-Visual (AV) aids. Post-test information was gathered after seven days from the Seven days was assigned after getting expert opinions as well as to give time for the implication of knowledge through the practice of growth monitoring with the help of an observational checklist. The sample characteristics were described by frequency, percentage and t-test were used to describe the difference between pre-test and post-test knowledge score.

Results: The Mean Pre-test knowledge score of the Anganwadi workers in the pre-test was $10.40 \pm 1.86$ and in post-test, it was $18.03 \pm 1.10$.Among $65 \%$ of Anganwadi workers had a very good level of practice score and $35 \%$ had an excellent level of practice score. Mean practice score of the Anganwadi workers was $12.26 \pm 1.20$ and mean percentage score was 81.77 \pm 8.03 .

Conclusion: It is important to give health education and teaching to the Anganwadi workers to improve the skills and upgradation of the new knowledge.

Key Words: Intervention, Growth and development assessment, Front line Health workers Comprehension, Skill, Kids under five, Pastoral area

\section{INTRODUCTION}

Development Monitoring will begin in the child's life, right from birth, at an early age. The Anganwadi Worker (AWW) will clarify the importance of weighing a newborn baby ideally on the same day of birth to the mother and other older people in the home. Development of ICDS is the key emblem of India's dedication to its children India's response to the challenge of, on the one hand, providing preschool education and breaking the vicious cycle of malnutrition, morbidity, decreased learning ability and mortality, with the most significant goals of improving the nutritional and health status of children aged 0-6 years to reduce the incidence of mortality, morbidity, malnutrition and school dropout; and enhance the mother's capacity to care for the child's normal health and nutritional needs through proper

\section{Corresponding Author:}

Ms Khushbu Meshram, Assistant Professor, Smt. Radhikabai Meghe Memorial College of Nursing, Datta Meghe Institute of Medical Sciences (Deemed to be University) Sawangi (Meghe) Wardha, Maharashtra, India; Email: khushbupande86@gmail.com

ISSN: 2231-2196 (Print)

Received: 16.06 .2020
ISSN: 0975-5241 (Online)

Revised: 27.07 .2020
Accepted: 17.08 .2020
Published: 07.12 .2020 
nutrition and health education. Role of Anganwadi workers is to provide Supplementary Care, Immunization, Dental Checkup, Referral Facilities, Pregnant \& Lactating Mother, Pre-School Education, and Care \& Dental Education for Children under 5 year. ${ }^{1}$

\section{MATERIALS AND METHODS}

A pre-experimental pre-test, the post-test research design was used in this interventional study. The study was conducted during December 2017 and the setting was selected in the rural area grampanchayat of Sawangi Meghe Wardha, after getting ethical permission(DMIMS (DU)/IEC/2017-18/6491 on dated $24 / 6 / 2017$, By using non-probability convenience sampling technique, 60 ASHA workers were Selected from the rural area based on the calculation.

Method of data collection: This consists of two sections Section 1: structured questionnaire Part I: demographic variable Part II: knowledge questionnaire and Section 2: the observational checklist.

\section{Methodology}

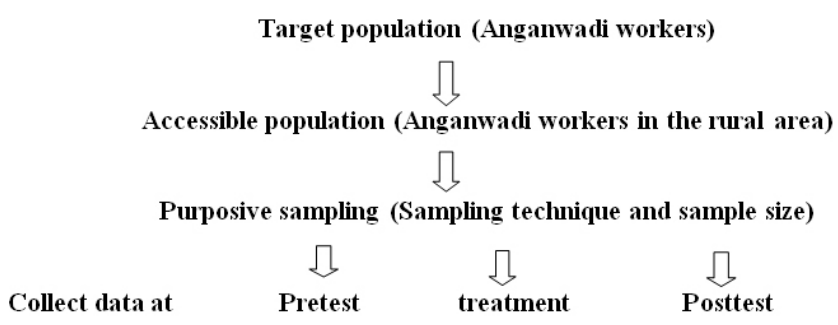

\section{Statistical Analysis}

The demographic data, collected in the pre-test stage, the analysis was done in terms of frequency and percentage. The paired t-test was used to compare pre and post-test knowledge scores. Chi-square test was applied to find out the association between the selected variable with practice score and posttest knowledge score. For statistical analysis, SPSS version 16.0 was used. The observational checklist used for checking the regular pattern of assessment of growth monitoring.

\section{RESULTS}

The study revealed that majority of the distribution of Anganwadi workers with regards to demographic variables. According to the rate and percentage of Anganwadi workers wise allocation age, family income and educational status and religion. Distribution of Anganwadi workers by age in years shows that $1 . \%$ of them belonged to the $25-30$ year age group, $28.3 \%$ to the $31-40$ year age group. $30 \%$ of the $41-50$ age group and $40 \%$ of the Anganwadi workers belonged to the 51-55 age group. According to their educational level reveals that $1.7 \%$ of them were educated up to primary standard, $58.3 \%$ up to secondary, $35 \%$ up to higher secondary and $5 \%$ were graduates.

Distribution of Anganwadi workers according to their experience in years reveals that $11.7 \%$ had the experience of 6 years, $30 \%$ of 8 years and $58.3 \%$ had the experience of more than 8 years. According to their religion reveals that $36.7 \%$ of them were Hindus and $63.3 \%$ were belonging to other religion. Distribution of Anganwadi workers according to their monthly family income shows that $23.3 \%$ had an income of $5000 \mathrm{Rs}, 15 \%$ had an income of 10000 Rs, $13.3 \%$ had an income of $15000 \mathrm{Rs}$ and $48.3 \%$ had an income of 20000 Rs per month. According to their marital status reveals that $98.3 \%$ of them were married and $1.7 \%$ was unmarried respectively. $95 \%$ of the Anganwadi workers underwent training for growth monitoring and 5\% need not got any type of training. $11.67 \%$ of Anganwadi workers in pre-test had an average level of knowledge score and $80 \%$ had a reasonable knowledge score in the pre-test, $8.33 \%$ in the pre-test and $5 \%$ in the posttest, and $95 \%$ of the posttest Anganwadi workers had an outstanding knowledge score Mean Pre-test knowledge score of the Anganwadi workers in pre-test was $10.40 \pm 1.86$ and in post-test. it was $18.03 \pm 1.10$. Study of the effectiveness of the planned teaching program on awareness of growth monitoring and practice among Anganwadi workers of less than five children The overall mean pretest and posttest knowledge scores of Anganwadi workers in rural Wardha district show that the posttest means knowledge score was higher than 18,03 with SD of $\pm 1,10$ compared to the mean pretest knowledge scoring (Table 1). The paired t-test of the Statistical Student implies that the difference in pre-test and post-test information among Anganwadi workers from Wardha district rural area was found to be 25.79 , which is statistically significant at a meaning level of $0.05 \%$ (Figure 1).

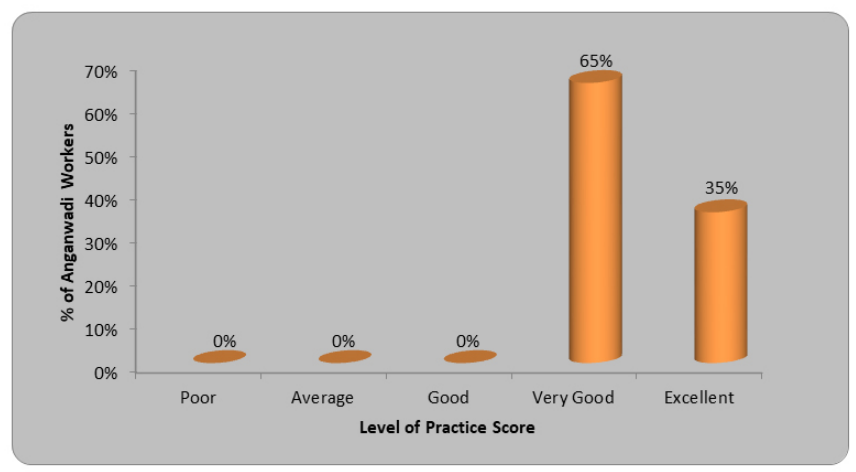

Figure 1: Distribution of under-five children with regards to practice regarding growth monitoring of under-five children.

The levels of practice were seen into 5 categories, poor, average, good, very good and excellent. $65 \%$ of Anganwadi 
workers had a very good level of practice score and 35\% had an excellent level of practice score. Mean practice score of the Anganwadi workers was 12.26 \pm 1.20 and mean percentage score was $81.77 \pm 8.03$.

The table shows the overall mean pre and posttest knowledge scores of Anganwadi workers in the rural district of Wardha, showing that post-testing means knowledge score was higher than the mean pretest knowledge score of 10.40 with SD of \pm 1.86 , with SD of \pm 1.10 . Therefore, the proposed teaching program on awareness of growth moni is statistically interpreted (Table 2).

\section{DISCUSSION}

The following study supported to the present study by Sangita Trivedi, Bharat C et al (1993), conducted a study to evaluate the utilization of integrated child Development Service scheme in children 1-6 years, in rural Integrated Child Development Service block in Madhya Pradesh. The study conducted in six Anganwadi areas in Integrated Child Development Service block (709 Children) and 5 randomly selected matched non Integrated Child Development Service rural areas (500 children) by adopting the door-to-door survey method to evaluate the nutritional and immunization services. $^{2}$

The study result indicates that the difference was not statistically important in two blocks for nutritional status, but interestingly, better immunization status was observed and the integratdchild development program blocked. Comparative data on nutritional status for the integrated child development service and the nonintegrated child development service block normal and grade III malnutrition, suggesting no substantial nutritional difference. Another supporting study was conducted by Walia and Gambhir S.K. (1978), conducted a study to evaluate the competence, knowledge and skills of Anganwadi Worker to some aspects of health care to affect their performance as paramedical workers in Nupur Bedi Block in Punjab. In this study, the 92 Anganwadi Worker's were included and the Investigator administered the structural questionnaire about the recording of weight, infant feeding, temperature, immunization procedures and treatment of minor ailments. The study findings show that only $46.5 \%$ knew about adjustment ' $\mathrm{O}$ ' $83.07 \%$ listed one month as an acceptable weighing period span 12.30 $\%$ understood that it would be helpful to weigh regularly babies. None of the staff understood the weight charts. ${ }^{3}$

Another study focused on awareness and skills of Anganwadi workers conducted by Tara Gopal Das Conducted a study (1998) on Anganwadi Worker's awareness and skills and activities in Baroda City slums through the adoption of the interview and participatory observation methods. The sample measurements were 25 . Results of the study show that all Anganwadi Employees were able to correctly perceive children's nutritional grade by using curved lines written on a child's weight as an indicator of growth retardation compared to a previous month, none of the workers interpreted a stationary weight as a significant sign of growth retardation. ${ }^{4}$

Another study focused on growth monitoring among the Anganwadi workers and knowledge up-gradation was found effective in improving the knowledge status of AWWs concerning growth monitoring. 5 It is revealed that in Integrated Child Development Service project Protein Energy Malnutrition -prevalence rate and incidence of low birth weight babies reduced. The quality of Anganwadi worker, which is conducted mainly by voluntary agency, needs improvements. The programme is catering primarily to children in the year 3-6 years age group. Nutritional therapy for severely malnourished children is not given an increased amount of supplementary nutrition. Growth Monitoring activities are done at times for detection of malnutrition. Irregular supply of supplementary nutrition due to difficulty in administration. ${ }^{6}$

Bharati etal. (2003) reviewed the assessment of health services offered at ICDS centres fr children aged 3to6 years and the knowledge of the extent of information and its use. Samples were taken from Jammu City's urban slums and included 15 Anganwadi employees and 30 parents attending Anganwadi centres. The inquiry was carried out by plans and findings of the interviews. The study showed that most of these centres are housed in a hygienic environment Parents find the best place to access free, cost-free wellness, education, and immunization and referral services. Play activities are carried out in 60 per cent of the Anganwadi centres to encourage healthy growth and children's development. Health cards were not issued to the beneficiaries by the Anganwadi staff, Yet their records and registers were kept and they were up to date. It was recommended that Health 28 Cards be issued to the beneficiaries to keep track of their children's health checks and immunization. ${ }^{7}$

\section{RECOMMENDATIONS}

A similar study can be conducted with more study participant to generalized the finding

Studies can be performed to determine the efficacy of the self-instruction module on parents Knowledge of growth monitoring

A study may be conducted to assess the current awareness among ASHA workers, staff nurses, and Anganwadi teachers about growth monitoring. 


\section{CONCLUSION}

Child growth rates are one of the finest indicators of a community's health. Monitoring development accompanied by effective intervention reduces illness, starvation and even death. It provides reassurance regarding the health of children and prevents parental anxiety. It helps classify children at risk of morbidity and mortality at Group and regional level. It, therefore, assists in the introduction of regional dietary and medical treatment services such as supplemental feeding, disadvantaged community diets, underserved school children, etc. It is also a method for evaluating programs for improving child health and nutrition and can form the basis for policymaking. The importance of nutrition in child growth and survival can be guided through growth monitoring of mothers, family and community, ultimately leading to better child-rearing practices. The Indian Pediatrics Academy, therefore, encourages all its representatives to regularly evolve.ICDS was also used as an important method to tackle obesity and morbidity and to reduce the problem of dropouts from college. This vital scheme has languished for many years, despite the findings of assessment studies and continuing criticism by NGOs regarding its lacunae, poor efficiency and the desperate need for support and revision. at all levels of society as a crucial time of growth and development. In recent years, however, India's poor child health and education indicators have caused concern and again centred on ICDS, and the role it can play in turning the situation around.

\section{ACKNOWLEDGEMENTS}

We would like to thank the authors whose works have cited and included in this study such as Altaf sehrish, prabhac shrivastava RK Singh GP, Singh Sp, Gupta Mk Kapil U,
Pradhan R. We acknowledge the immense help received from the scholars whose articles are cited and included in references of this manuscript. We are also grateful to authors/ editors/publishers of all those articles, journals and books from where the literature for this article has been reviewed and discussed.

\section{Conflict of interest: Nil}

Financial support: Self

\section{REFERENCES}

1. National Institute of Public Cooperation and Child Development growth monitoring manual 5, Siri Institutional Area, Hauz Khas, New Delhi-110016egm. pdf [Internet]. [cited 2020 Jun 11]. Available from: https://www.nipccd.nic.in/file/elearn/manual/ egm.pdf

2. National rural health mission Meeting people's health needs in rural areas Ministry of Health and Family Welfare Government of India Nirman Bhawan New Delhi-110001 nrhm-frameworklatest.pdf [Internet]. [cited 2020 Jun 11]. Available from: https:// nhm.gov.in/WriteReadData/1892s/nrhm-framework-latest.pdf

3. National Institute of Public Cooperation and Child Development Research on ICDS An Overview Volume 2,5, Siri Institutional Area, Hauz Khas, New Delhi - 110016..pdf [Internet]. [cited 2020 Jun 11]. Available from: http://www.nipccd-earchive.wcd. nic.in/sites/default/files/PDF/38b\%20\%20icdsvol2.pdf

4. Altaf S. A Study of the functioning of two Anganwadi centres in Baramulla, Kashmir. :101. Dspace.tiss.edu > jspui > bitstream

5. Prabha C, Srivastava RK, Singh GP, Singh SP, Gupta MK. An intervention to improve the knowledge of Anganwadi workers pertaining to growth monitoring in rural areas of Varanasi district, India. Int J Res Med Sci 2017 Jan;4(6):2030-8.

6. Kapil U, Pradhan R. Integrated child development services scheme (ICDS) in India: its activities, present status and future strategy to reduce malnutrition. J Indian Med Assoc 2000 Sep;98(9):559-60.

7. Kawle L. Socio economic conditions of anganawadi workers a case study of raichur district. Ph.D Thesis. 2015. http://hdl. handle.net/10603/37010

Table 1: Percentage wise distribution of anganwadi workers according to their demographic characteristics $(\mathbf{n}=60)$

$\begin{array}{lcc}\text { Demographic Variables } & \text { Frequency } & \text { Percentage } \\ \text { Age in years } & & 1.7 \\ 25-30 \text { yrs } & 17 & 28.3 \\ 31-40 \text { yrs } & 18 & 30 \\ 41-50 \text { yrs } & 24 & 40 \\ 51-55 \text { yrs } & & \\ \text { Educational Level } & 1 & 1.7 \\ \text { Primary } & 35 & 58.3 \\ \text { Secondary } & 21 & 35 \\ \text { Higher Secondary } & 3 & 5\end{array}$


Table 1: (Continued)

\begin{tabular}{|c|c|c|}
\hline Demographic Variables & Frequency & Percentage \\
\hline \multicolumn{3}{|l|}{ Experience in years } \\
\hline 2 years & o & o \\
\hline 6 years & 7 & 11.7 \\
\hline 8 years & 18 & 30 \\
\hline$\geq 9$ years & 35 & 58.3 \\
\hline \multicolumn{3}{|l|}{ Religion } \\
\hline Hindu & 22 & 36.7 \\
\hline Muslim & o & o \\
\hline Buddhist & o & o \\
\hline Others & 38 & 63.3 \\
\hline \multicolumn{3}{|c|}{ Monthly Family Income(Rs) } \\
\hline 5000 Rs & 14 & 23.3 \\
\hline $10000 \mathrm{Rs}$ & 9 & 15 \\
\hline 15000 Rs & 8 & 13.3 \\
\hline 20000 Rs & 29 & 48.3 \\
\hline \multicolumn{3}{|l|}{ Marital Status } \\
\hline Married & 59 & 98.3 \\
\hline Unmarried & 1 & 1.7 \\
\hline Widow & o & o \\
\hline \multicolumn{3}{|c|}{ Previous training regarding growth monitoring } \\
\hline Yes & 57 & 95 \\
\hline No & 3 & 5 \\
\hline
\end{tabular}

Table 2: Significance of difference between knowledge scores in pre and post-test of Anganwadi workers regarding growth monitoring of under-five children $(n=60)$

\begin{tabular}{lccccc} 
Overall & Mean & SD & Mean Difference & t-value & p-value \\
Pre Test & 10.40 & 1.86 & $7.63 \pm 2.29$ & 25.79 & $0.0001, S$ \\
Post Test & 18.03 & 1.10 & & & \\
\hline
\end{tabular}

